\title{
CALIBRAÇÃO DE EXTRATORES PROVIDOS DE CÁPSULA POROSA PARA MONITORAMENTO DA SALINIDADE E DA CONCENTRAÇÃO DE ÍONS
}

\section{FRANCISCO DE A. DE OLIVEIRA ${ }^{1}$, JOSÉ F. DE MEDEIROS ${ }^{2}$, SERGIO N. DUARTE ${ }^{3}$, MANOEL J. DA SILVA JÚNIOR ${ }^{4}$, CHARLLES M. CAMPELO ${ }^{5}$}

\begin{abstract}
RESUMO: Os resultados satisfatórios obtidos no monitoramento da salinidade e concentração de íons na solução do solo, usando extratores de cápsulas porosas, motivaram a realização deste trabalho, o qual teve como objetivo a obtenção de curvas de calibração para estes extratores monitorarem a condutividade elétrica e a concentração de nitrato e de potássio na solução de dois tipos de solo (Latossolo Vermelho-Amarelo Argissólico franco arenoso, e o outro como Cambissolo Eutrófico), em Mossoró - RN. As concentrações de nitrato utilizadas foram as mesmas nos dois solos $\left(0 ; 84 ; 168 ; 252 ; 336 ; 420\right.$ e $\left.504 \mathrm{mg} \mathrm{L}^{-1}\right)$; quanto ao potássio, foram utilizadas concentrações diferentes no solo arenoso $\left(0 ; 117 ; 234 ; 351 ; 468 ; 585\right.$ e $\left.702 \mathrm{mg} \mathrm{L}^{-1}\right)$ e no argiloso $(0 ; 117 ; 234$; $351 ; 468 ; 585 ; 702 ; 1.170 ; 1.755 ; 2.340 ; 2.925$ e $3.510 \mathrm{mg} \mathrm{L}^{-1}$ ). A condutividade elétrica da solução do solo e a concentração de nitrato e de potássio foram estimadas com precisão satisfatória a partir da solução coletada com extratores providos de cápsulas porosas, sendo necessária uma calibração prévia para cada tipo de solo.
\end{abstract}

PALAVRAS-CHAVE: solução do solo, condutividade elétrica, potássio, nitrogênio.

\section{CALIBRATION OF POROUS CERAMIC CUP EXTRACTORS IN MONITORING SOIL SALINITY AND ION CONCENTRATION}

SUMARY: The satisfactory results obtained in monitoring soil salinity and ion concentration, by means of porous ceramic cup extractors, motivated the realization of this study, which objective was obtaining calibration curves for these extractors to monitor soil electrical conductivity and concentration of nitrate and potassium in two different soils. The nitrate concentrations tested were the same for the two soils $\left(0 ; 84 ; 168 ; 252 ; 336 ; 420\right.$ and $\left.504 \mathrm{mg} \mathrm{L}^{-1}\right)$ but, for potassium, different concentrations were used for sandy soil $\left(0 ; 117 ; 234 ; 351 ; 468 ; 585\right.$ and $\left.702 \mathrm{mg} \mathrm{L}^{-1}\right)$ and clay soil $\left(0 ; 117 ; 234 ; 351 ; 468 ; 585 ; 702 ; 1,170 ; 1,755 ; 2,340 ; 2,925\right.$ and $\left.3,510 \mathrm{mg} \mathrm{L}^{-1}\right)$. Electrical conductivity of soil solution and concentrations of nitrate and potassium were estimated with satisfactory precision from soil solution collected with porous ceramic cup extractors, but this task must be preceded by a calibration for each soil type.

KEYWORDS: soil solution, electrical conductivity, potassium, nitrogen.

\footnotetext{
${ }^{1}$ Prof. Assistente, Departamento de Ciências Ambientais e Tecnológicas, UFERSA, BR-110, km 47, Mossoró - RN, thikaoamigao@bol.com.br

${ }^{2}$ Engoㅡ Agrônomo, Depto. de Ciências Ambientais e Tecnológicas, UFERSA - Mossoró - RN, jfmedeir@ufersa.edu.br.

${ }^{3}$ Prof. Associado, Depto. de Engenharia de Biossistemas, ESALQ/USP, Piracicaba - SP, snduarte@esalq.usp.br.

${ }^{4}$ Prof. Adjunto, Depto. de Ciências Ambientais e Tecnológicas, UFERSA, Mossoró - RN, mjanuario@ufersa.edu.br.

${ }^{5}$ Eng ${ }^{\text {o }}$ Agrônomo, Mossoró - RN, charllesufersa@hotmail.com

Recebido pelo Conselho Editorial em: 22-6-2009

Aprovado pelo Conselho Editorial em: 16-3-2011
} 


\section{INTRODUÇÃO}

A fertirrigação tem-se destacado como a tecnologia de maior impacto na produção agrícola, possibilitando a distribuição de nutrientes durante o ciclo da cultura de acordo com a necessidade nutricional das plantas, reduzindo riscos de desperdício de fertilizantes e contaminação ambiental. A disponibilidade dos íons para as raízes das plantas é controlada por várias reações, equilíbrio entre ácido e base, complexação iônica, precipitação e dissolução de sólidos, oxidação, redução e trocas iônicas.

LAO et al. (2004) reforçam que os níveis dos nutrientes da solução do solo devem ser conhecidos para estabelecer a aproximação apropriada ao manejo dos nutrientes. O conhecimento da condutividade elétrica do solo e da composição química da solução no solo é importante para verificar a disponibilidade de nutrientes e a toxidez de íons específicos ao longo do ciclo da cultura. Entretanto, o monitoramento por análise periódica do solo, com a finalidade de acompanhar as concentrações dos íons na solução, durante as fases de crescimento e desenvolvimento da cultura, é inviável economicamente em uma atividade agrícola comercial, além de não ser uma metodologia instantânea, que possibilita tomada de decisão imediata.

O mais sensato, portanto, seria racionalizar o manejo da fertirrigação, determinando a condutividade elétrica e/ou a concentração parcial de íons na solução do meio, e, neste contexto, a extração da solução do solo por intermédios de cápsulas porosas surge como uma alternativa, a um custo relativamente reduzido, capaz de ser aplicada a situações de campo (SILVA et al., 2000; DIAS et al., 2005).

DIAS et al. (2005) avaliaram o uso de extratores de solução por cápsulas porosas para o monitoramento da concentração total de sais na solução do solo, verificando que esta tecnologia pode ser utilizada com satisfatória precisão. JIMÉNEZ et al. (2006) verificaram que cápsulas de sucção podem ser usadas para extrair a solução do solo, porque obtém a amostra da solução do solo sem diluição para posterior análise.

$\mathrm{Na}$ literatura, são encontrados resultados que apresentam diferentes correlações para concentração de íons na solução obtida pelo método da pasta saturada e com uso de cápsulas porosas, evidenciando a necessidade de calibração de extratores providos de cápsulas porosas para cada tipo de solo. Este trabalho foi desenvolvido com o objetivo de determinar curvas de calibração para extratores de solução providos de cápsulas porosas para o monitoramento da concentração de nitrogênio, potássio e da condutividade elétrica na solução de dois materiais de solo.

\section{MATERIAL E MÉTODOS}

O trabalho foi realizado nos laboratórios de solos e de irrigação e salinidade, e em casa de vegetação do Departamento de Ciências Ambientais da Universidade Federal Rural do Semiárido (UFERSA), Mossoró-RN, localizada nas coordenadas geográficas de $5^{\circ} 11^{\prime}$ de latitude sul e $37^{\circ} 20^{\prime}$ de longitude oeste de Greenwich, com altitude média de $18 \mathrm{~m}$.

A pesquisa foi desenvolvida utilizando-se amostras da camada de 0 a $20 \mathrm{~cm}$ de dois solos, sendo um de textura arenosa e outro de textura argilosa, classificados como Latossolo Vermelho-Amarelo Argissólico franco arenoso, e o outro como Cambissolo Vermelho Amarelo-Eutrófico, argila de atividade alta a fraca (EMBRAPA, 1999).

Ambos os materiais foram coletados na camada de 0 a $20 \mathrm{~cm}$ do perfil, em áreas de terra virgem. Amostra de solo arenoso foi coletada em área de mata, na Fazenda experimental da UFERSA "Rafael Fernandes", distante $21 \mathrm{~km}$ de Mossoró. O material de solo argiloso foi coletado em área de solo virgem, pertencente a Empresa WG Fruticultura, localizada na zona rural do município de Baraúna - RN, distante cerca de $30 \mathrm{~km}$ da sede do município de Mossoró - RN. 
Os materiais coletados foram postos para secar à sombra, em seguida peneirados em malha de 2,0 mm e submetidos a análises químicas e físico-hídricas, cujos resultados são apresentados na Tabela 1.

TABELA 1. Características físicas e químicas dos solos utilizados no experimento. Physical and chemical characteristics of the soils used in the experiment.

\begin{tabular}{|c|c|c|c|c|c|c|c|c|c|c|}
\hline Solo* & $\mathrm{pH}$ & $\begin{array}{l}\text { M.O. } \\
(\%)\end{array}$ & $\begin{array}{c}\mathrm{P} \\
\left(\mathrm{mg} \mathrm{dm}^{-3}\right)\end{array}$ & $\mathrm{K}$ & $\mathrm{Na}$ & $\mathrm{Ca}$ & $\begin{array}{r}\mathrm{Mg} \\
-(\mathrm{cmc}\end{array}$ & $\begin{array}{c}\mathrm{Al} \\
\left.\mathrm{dm}^{-3}\right)\end{array}$ & $\mathrm{H}$ & CTC \\
\hline Argiloso & 7,1 & 1,70 & 5,00 & 0,87 & 0,79 & 4,00 & 1,10 & 0,00 & 2,48 & 9,24 \\
\hline Arenoso & 5,3 & 1,05 & 2,20 & 0,14 & 0,13 & 0,40 & 0,60 & 0,25 & 3,05 & 4,57 \\
\hline & & \multicolumn{2}{|c|}{$\begin{array}{l}\text { Densidade } \\
\left(\mathrm{kg} \mathrm{m}^{-3}\right)\end{array}$} & \multicolumn{2}{|c|}{ Areia } & \multicolumn{3}{|c|}{ Silte } & \multicolumn{2}{|c|}{ Argila } \\
\hline Argiloso & & \multicolumn{2}{|c|}{1,30} & \multicolumn{2}{|c|}{450} & \multirow{2}{*}{\multicolumn{3}{|c|}{250}} & \multicolumn{2}{|c|}{300} \\
\hline Arenoso & & \multicolumn{2}{|c|}{1,50} & \multicolumn{2}{|c|}{820} & & & & \multicolumn{2}{|c|}{140} \\
\hline
\end{tabular}

* Solo argiloso - Cambissolo; Solo arenoso - Latossolo Vermelho-Amarelo (EMBRAPA, 1999).

Foram aplicadas soluções com diferentes concentrações de nitrato e de potássio, mantendo-se constante todos os outros nutrientes (Tabela 2), utilizando-se como padrão (100\%) da solução nutritiva recomendada para hidroponia em sistema NFT (Nutient Film Technique), conforme CASTELLANE \& ARAÚJO (1994).

Para o solo arenoso, foram utilizadas 7 concentrações de nitrato $(0 ; 84 ; 168 ; 252 ; 336 ; 420$ e $\left.504 \mathrm{mg} \mathrm{L}^{-1}\right)$ e 7 concentrações de potássio $\left(0 ; 117 ; 234 ; 351 ; 468 ; 585\right.$ e $\left.702 \mathrm{mg} \mathrm{L}^{-1}\right)$, resultando em 14 soluções de diferentes concentrações, sendo os níveis de nitrato combinado com o nível de $234 \mathrm{mg} \mathrm{L}^{-1}$ de potássio, e os níveis de potássio, combinados com o nível de $168 \mathrm{mg} \mathrm{L}^{-1}$ de nitrato. Os fertilizantes utilizados como fontes de potássio e de nitrato foram: nitrato de cálcio, nitrato de potássio e cloreto de potássio.

Para o solo argiloso, foi adotado o mesmo procedimento utilizado no solo arenoso; no entanto, devido a ter sido observado alto poder tampão do solo em relação a esse nutriente, foi necessário utilizar níveis maiores de potássio, para que fosse possível ajustar equação de resposta. Assim, foram adotados os mesmos níveis de nitrato $\left(0 ; 84 ; 168 ; 252 ; 336 ; 420\right.$ e $\left.504 \mathrm{mg} \mathrm{L}^{-1}\right)$, aumentando os níveis de potássio $(0 ; 117 ; 234 ; 351 ; 468 ; 585 ; 702 ; 1.170 ; 1.755 ; 2.340 ; 2.925$ e $3.510 \mathrm{mg} \mathrm{L}^{-1}$ ), resultando assim 7 concentrações de nitrato e 12 concentrações de potássio. Antes da aplicação da solução nos vasos, foram feitas leituras de condutividade elétrica, utilizando-se de um condutivímetro de bancada (Tabela 2), cujos resultados são mostrados na Tabela 2.

Para o preparo das soluções, foram utilizados os seguintes sais: $\mathrm{KH}_{2} \mathrm{PO}_{4}, \mathrm{KNO}_{3}$, $\mathrm{Ca}\left(\mathrm{NO}_{3}\right)_{2} 4 \mathrm{H}_{2} \mathrm{O}, \mathrm{MgSO}_{4} 7 \mathrm{H}_{2} \mathrm{O}, \mathrm{KCl}, \mathrm{CaCl}_{2} 2 \mathrm{H}_{2} \mathrm{O}$ e $\mathrm{NaNO}_{3}$, sendo estes sais dissolvidos em água proveniente de um poço profundo, localizado no Câmpus central da UFERSA. Para a água utilizada no preparo das soluções, são apresentadas as seguintes características: $\mathrm{CE}=0,50 \mathrm{dS} \mathrm{m}{ }^{-1} ; \mathrm{pH}=8,30$; $\mathrm{Ca}=2,10 ; \mathrm{Mg}=1,10 ; \mathrm{K}=0,30 ; \mathrm{Na}=2,30 ; \mathrm{Cl}=1,80 ; \mathrm{HCO} 3=3,00$ e $\mathrm{CO} 3=0,20\left(\mathrm{mmol}_{\mathrm{C}} \mathrm{L}^{-1}\right)$.

Amostras das duas classes de solo foram acondicionadas em vasos plásticos com capacidade para $5 \mathrm{~kg}$ de solo, em quantidade predeterminada, de forma a apresentarem a densidade natural de cada solo. Em cada vaso, foi instalado um extrator de solução provido de cápsula porosa na profundidade de $10 \mathrm{~cm}$, e em seguida, foram aplicados às soluções padrões predeterminados, de forma que o volume de solução aplicada em cada vaso fosse suficiente para umedecer o solo até atingir a umidade referente à capacidade máxima de retenção. $\mathrm{O}$ extrator foi construído com um tubo de PVC, acoplado a uma cápsula de cerâmica porosa de $20 \mathrm{~mm}$ de diâmetro e $50 \mathrm{~mm}$ de comprimento em sua extremidade inferior, e na parte superior, o extrator era vedado com borracha. 
TABELA 2. Concentração de nitrogênio, potássio e condutividade elétrica das soluções utilizadas na fase de calibração dos extratores de cápsulas porosas. Concentration of nitrogen, potassium and electrical conductivity of the solutions used during the calibration of the porous ceramic cup extractors.

\begin{tabular}{|c|c|c|c|c|c|}
\hline Nitrogênio & Potássio & 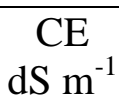 & $\begin{array}{l}\text { Nitrogênio } \\
-\end{array}$ & Potássio & $\begin{array}{c}\mathrm{CE} \\
\mathrm{dS} \mathrm{\textrm {m } ^ { - 1 }}\end{array}$ \\
\hline \multicolumn{3}{|c|}{-------- Solo Arenoso -------- } & \multicolumn{3}{|c|}{--------- Solo Argiloso --------- } \\
\hline 0 & 234 & 1,60 & 234 & 0 & 1,60 \\
\hline 84 & 234 & 2,00 & 234 & 84 & 2,00 \\
\hline 168 & 234 & 1,60 & 234 & 168 & 1,60 \\
\hline 252 & 234 & 1,98 & 234 & 252 & 1,98 \\
\hline 336 & 234 & 2,59 & 234 & 336 & 2,59 \\
\hline 420 & 234 & 3,38 & 234 & 420 & 3,38 \\
\hline 504 & 234 & 3,56 & 234 & 504 & 3,56 \\
\hline 168 & 0 & 1,36 & 168 & 0 & 1,36 \\
\hline 168 & 117 & 1,69 & 168 & 117 & 1,69 \\
\hline 168 & 234 & 1,70 & 168 & 234 & 1,70 \\
\hline 168 & 351 & 2,38 & 168 & 351 & 2,38 \\
\hline 168 & 468 & 2,90 & 168 & 468 & 2,90 \\
\hline 168 & 585 & 2,91 & 168 & 585 & 2,91 \\
\hline 168 & 702 & 0,76 & 168 & 702 & 0,76 \\
\hline- & - & - & 168 & 1.170 & 4,75 \\
\hline - & - & - & 168 & 1.755 & 6,78 \\
\hline- & - & - & 168 & 2.340 & 8,41 \\
\hline- & - & - & 168 & 2.925 & 10,13 \\
\hline- & - & - & 168 & 3.510 & 12,15 \\
\hline
\end{tabular}

As soluções foram aplicadas manualmente, utilizando-se de um Becker de $500 \mathrm{~mL}$. Após a instalação dos extratores e o umedecimento do solo, o material foi incubado por um período de $24 \mathrm{~h}$, quando foi aplicado um vácuo em torno de $70 \mathrm{kPa}$. Optou-se por aplicar este valor de vácuo por ser este próximo aos empregados por vários pesquisadores, para diversos tipos de solos (SILVA et al., 2000; MARCUSSI et al., 2004; SOUZA et al., 2006; MEDEIROS et al., 2009; QUEIROZ et al., 2009). Cerca de 12 h após a aplicação do vácuo, coletaram-se as amostras da solução de solo de cada extrator, sendo em seguida armazenadas em copos coletores previamente identificados.

Nestas amostras, foram determinadas as concentrações de nitrato e de potássio. O nitrato foi determinado utilizando um medidor de íon compacto Horiba ${ }^{\circledR}$ (GLOAGUEN et al., 2009), que utiliza eletrodo seletivo, e o K, determinado através do fotômetro de chama. Este procedimento foi repetido mais duas vezes a cada dois dias. Simultaneamente, foram feitas leituras da condutividade elétrica da solução do solo, coletada através dos extratores, para serem feitas curvas de calibração, sendo consideradas como valores de referência as condutividades elétricas da solução aplicada (Tabela 2).

Com os resultados das análises, foram ajustadas curvas para correlacionar a concentração dos íons obtidos nas amostras de solução do solo coletada nos extratores de cápsulas porosas com a concentração desses íons aplicada na solução.

\section{RESULTADOS E DISCUSSÃO}

\section{Calibração dos extratores para a determinação da condutividade elétrica da solução do solo}

A relação entre a condutividade elétrica da solução aplicada e a condutividade elétrica da solução coletada com o auxílio dos extratores é apresentada na Figura 1. Pode-se constatar que equações lineares possibilitam estimar condutividade da solução do solo a partir de solução coletada 
com extratores de cápsula porosa. Para ambos os materiais de solo, as equações que apresentaram maior ajuste foram do tipo linear, apresentando satisfatório coeficiente de determinação $\left(\mathrm{R}^{2}>0,93\right)$. Para o solo arenoso, foi observado que houve correlação entre a condutividade elétrica da solução aplicada e a condutividade elétrica da solução coletada; no entanto, com um coeficiente angular maior que 1, evidenciando assim que a condutividade da solução foi maior que da solução-padrão aplicada (Figura 1A). Para o solo argiloso, verifica-se que o coeficiente angular foi menor que 1; assim, pode-se constatar uma redução da condutividade elétrica da solução em comparação com a condutividade da solução aplicada (Figura 1B).

(A)

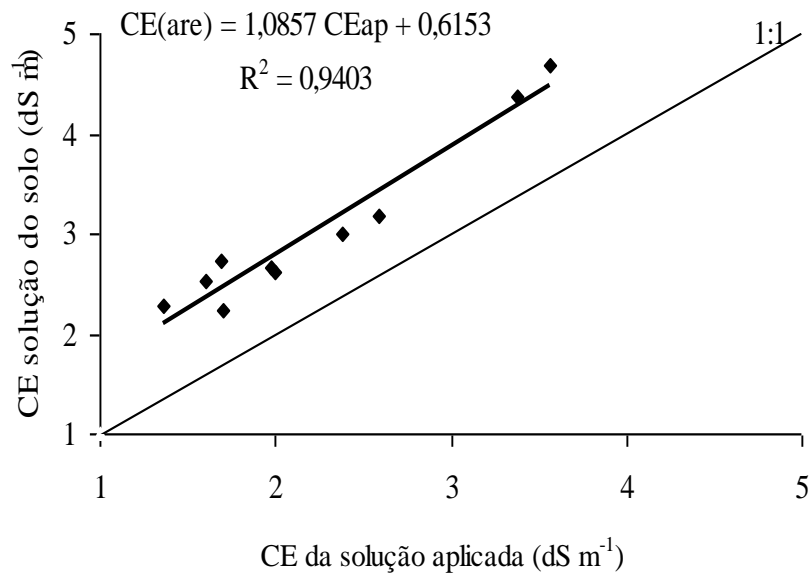

(B)

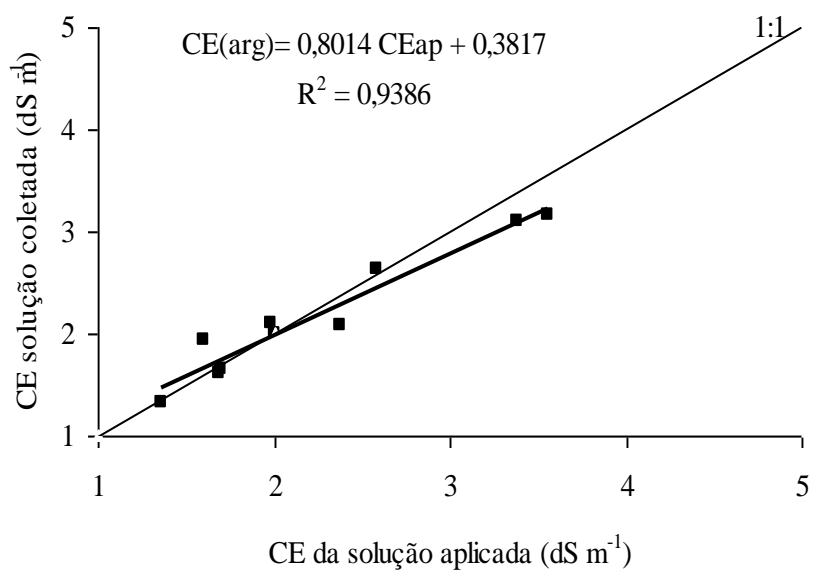

FIGURA 1. Relação entre a condutividade da solução do solo, corrigida para capacidade de armazenamento de água, coletada com extratores de solução e condutividade da solução-padrão aplicada em solo arenoso (A) e argiloso (B). Relationship between the conductivity of soil solution, corrected for storage capacity of water, collected with extractors solution and the conductivity standard solution used in sandy soil (A) and clay soil (B).

Analisando a relação entre os valores da condutividade elétrica medida na solução coletada com a solução aplicada, nos dois tipos de solo, verifica-se que ocorreu aumento em ambos os solos de acordo com o incremento da condutividade da solução aplicada, apesar de cada nível salino ser menor na solução do solo argiloso. Segundo QUEIROZ et al. (2005), solos arenosos apresentam baixa capacidade de retenção de água e íons; assim, maiores quantidades dos sais aplicados aos solos arenosos permanecem em solução, elevando a salinidade do solo, se comparados a solos com maiores teores de argila em sua composição.

A condutividade elétrica depende, além de outros fatores, do número de cargas iônicas presentes na solução, cargas das espécies iônicas, mobilidade de cada íon, área efetiva dos eletrodos e distância entre os eletrodos (FERREIRA \& MARTINEZ, 1997). Para RICHARDS (1954), o teor e o tipo de argila predominante no solo podem agir como interferentes na concentração de íons na solução e, consequentemente, no valor da CE. A argila age como um acumulador de íons por meio sistemático de adsorção e posterior dessorção iônica, sendo influenciada principalmente pela temperatura e pela concentração iônica da solução. Assim, quanto maior as concentrações de íons específicos, maior será a adsorção deste no complexo coloidal.

DIAS et al. (2005) ressaltam que a utilização do método de medição da condutividade elétrica da solução obtida com extrator de cápsula porosa é bastante eficiente, devido a sua facilidade, versatilidade e praticidade, quando se compara com o da solução diluída 1:2, desde que sejam conhecidas a umidade da pasta saturada e a umidade no momento da extração. A diferença entre a relação encontrada e a curva 1:1 (aplicada:coletada) pode estar associada à dinâmica de solutos no solo e á metodologia empregada para extrair os solutos no solo. A diferença encontrada para os 
diferentes tipos de solos pode ainda ser atribuída a diferença de textura, uma vez que, para ambos os solos, foi aplicada a mesma intensidade de vácuo, e, segundo SPOSITO (1989), uma das principais dificuldades é a variação na granulometria, já que a concentração de solutos é variável de acordo com o vácuo aplicado e a dimensão do poro.

\section{Calibração dos extratores para determinação de potássio}

Para a curva de calibração da concentração de potássio na solução do solo, foi verificado comportamento diferente nos dois tipos de solos avaliados. Para ambos os solos, foi observada redução na concentração de potássio coletado da solução do solo em comparação com as concentrações nas soluções aplicadas (Figura 2A e 2B), sendo o efeito mais notável no solo argiloso. Pressupõe-se que a concentração de K na solução do solo, para a aplicação da dose zero, corresponde à concentração natural de potássio no solo.

Para o solo argiloso, não foi possível obter resposta para o potássio quando se aplicaram as mesmas concentrações utilizadas no solo arenoso, de forma que foi necessário aplicar soluções mais concentradas para que se pudesse obter resposta. Pode-se perceber, assim, na Figura 2B, que nas soluções-padrão de concentração de até $468 \mathrm{mg} \mathrm{L}^{-1}$ de potássio, este elemento não ficou disponibilizado para solução do solo, apresentando valores próximos à concentração de potássio natural do solo $\left(0,87 \mathrm{cmol}_{\mathrm{c}} \mathrm{dm}^{-3}\right)$. Verifica-se que parte do potássio aplicado ficou adsorvido nos coloides do solo, fato esse que pode ser explicado pela maior capacidade de troca de carga do solo argiloso (Tabela 1).

(A)

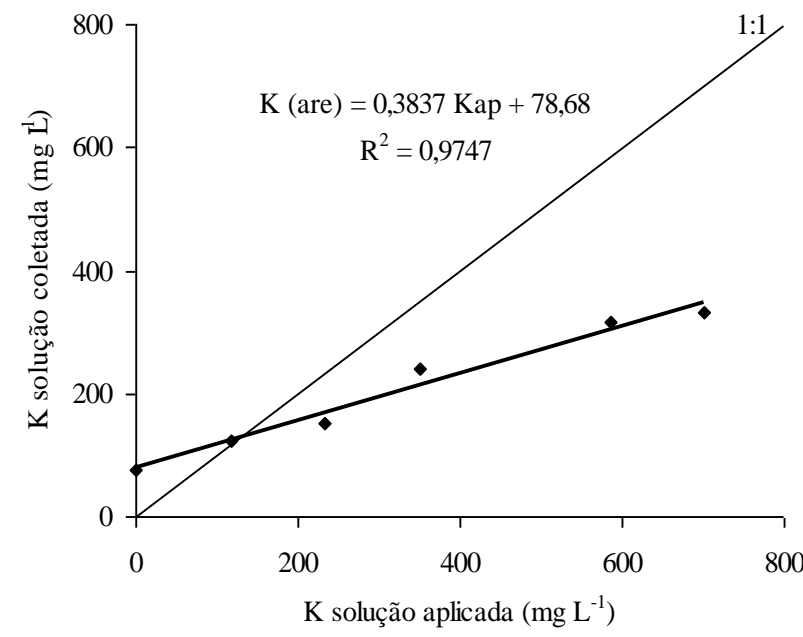

(B)

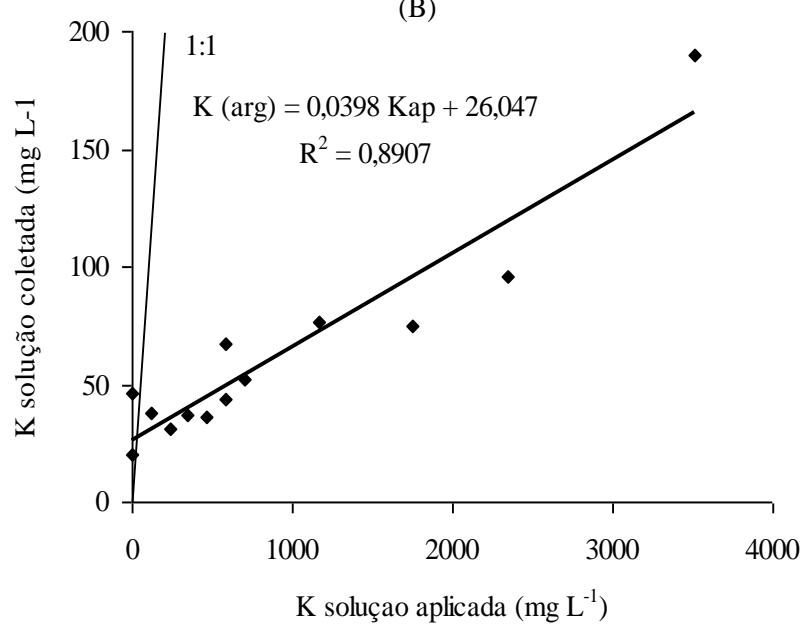

FIGURA 2. Relação entre a concentração de potássio na solução coletada com o uso de extratores de solução e das soluções aplicadas em amostras de solo arenoso (A) e argiloso (B). Relationship between the potassium concentration in the solution collected with the use of extractors solution and the solutions applied in samples of sandy soil (A) and clay soil (B).

COSTA et al. (2000) avaliaram a extração de potássio por três tipos de cápsulas porosas e constataram que a concentração de $\mathrm{K}$ na solução extraída foi menor do que a concentração na solução aplicada. De acordo com MEURER \& ANGHINONI (1993), o potássio apresenta elevada mobilidade no solo; assim, a disponibilidade deste nutriente para as plantas depende das características mineralógicas, físicas e químicas de cada solo.

No rol dos cátions trocáveis, pela sua valência e raio iônico hidratado, o potássio ocupa o antepenúltimo lugar quanto à seletividade de adsorção (série liotrópica), o que em si é um fator favorável à sua substituição, pois, em condições de igualdade de concentração, é adsorvido na sobra de cargas após o preenchimento por $\mathrm{H}^{+} \gg>\mathrm{Al}^{3+}>\mathrm{Ca}^{2+}>\mathrm{Mg}^{2+}$, resultando assim em elevada lixiviação de $\mathrm{K}$ em solos bem drenados, principalmente em solos com menor CTC (RAIJ et al., 2001). 
WERLE et al. (2008) avaliaram a lixiviação de potássio em dois solos de diferentes texturas (média e argilosa) e verificaram maior concentração de $\mathrm{K}$ liberado na solução lixiviada do solo arenoso. Segundo esses autores, a CTC é o principal componente que determina a maior ou menor relação $\mathrm{K}$ trocável/K da solução, isto é, para uma mesma quantidade de $\mathrm{K}$ total, haverá menos $\mathrm{K}$ na solução em solos com alta CTC, o que refletirá em menores concentrações de K na solução.

\section{Calibração dos extratores de solução para determinação de nitrogênio}

Para a determinação da concentração de nitrato na solução do solo coletada com os extratores de solução, os valores obtidos pelo medidor portátil (Horiba) foram convertidos para nitrogênio $\left(\mathrm{N}_{2}\right)$ pela relação entre a leitura da cartela e o fator de conversão $(4,42)$.

Para o solo arenoso, a equação de regressão de melhor ajuste foi do tipo linear, apresentando satisfatório coeficiente de correlação $\left(\mathrm{R}^{2}=0,9821\right)$, apresentando teor de $\mathrm{N}$ na solução coletada com os extratores maior que a concentração da solução aplicada. Essa resposta pode ser devido ao substrato utilizado apresentar considerado teor de $\mathrm{N}(73,468)$, correspondente ao coeficiente angular da equação de regressão. Além do teor de $\mathrm{N}$ natural do solo, verifica-se aumento no teor de $\mathrm{N}$, na solução coletada em cerca de $20 \%$ maior que o teor de $\mathrm{N}$ na solução aplicada, podendo este fato ser atribuída a um maior movimento de $\mathrm{N}$ na solução do solo (Figura 3A). ROSSI et al. (2007) avaliaram a movimentação de íons de nitrato em colunas de solo, utilizando amostras deformadas e indeformadas. Esses autores verificaram que íon nitrato percorre praticamente o dobro da distância na amostra indeformada em comparação à deformada, como a utilizada neste experimento.

$\mathrm{O}$ teor de $\mathrm{N}$ na solução coletada com os extratores no solo argiloso também apresentou valores maiores que o teor de $\mathrm{N}$ da solução aplicada, sendo a equação linear a que melhor representa a relação $\left(\mathrm{R}^{2}=0,9917\right)$. Esse aumento pode ser devido principalmente ao teor de $\mathrm{N}$ natural do solo $\left(51,452 \mathrm{mg} \mathrm{L}^{-1}\right)$, no entanto verifica-se que a equação de regressão apresenta um coeficiente linear menor que 1 (hum), apresentando assim tendência de redução na concentração, na solução coletada, em relação à solução aplicada (Figura 3B).

(A)

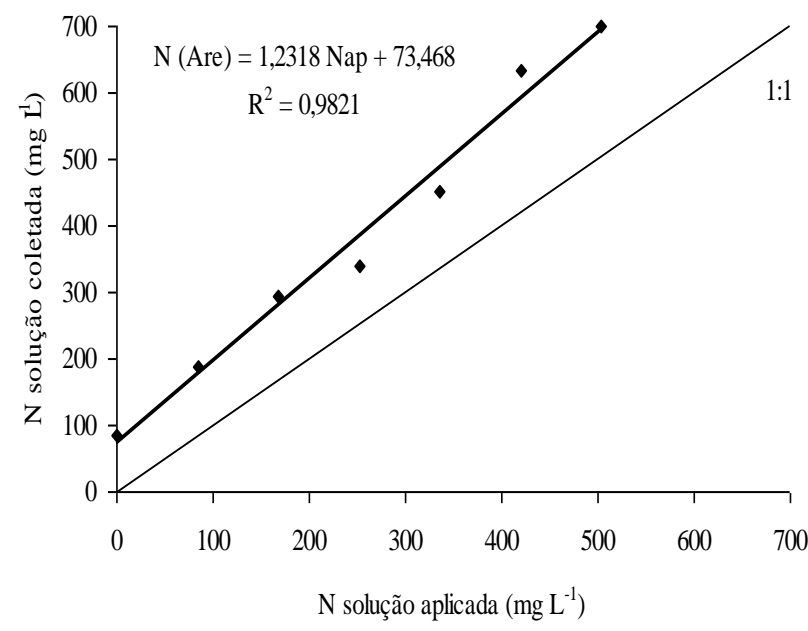

(B)

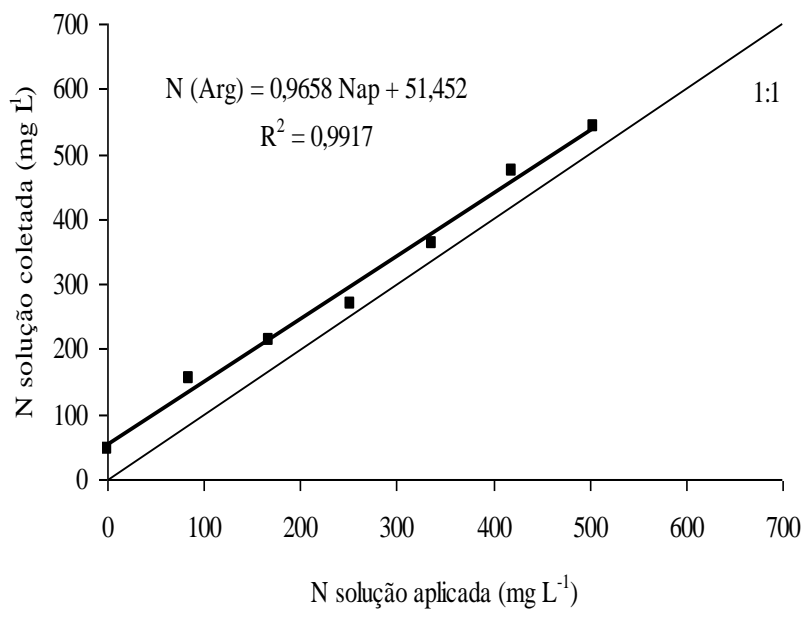

FIGURA 3. Relação entre a concentração de nitrogênio na solução coletada no solo por extratores e das soluções aplicadas em amostras de solo arenoso (A) e argiloso (B). Relationship between the concentration of nitrogen in the soil solution collected by extractors and the solutions applied in samples of sandy soil (A) and clay soil (B).

Ainda na Figura 3, pode-se observar uma diferença bastante expressiva nos teores de nitrato e potássio nos diferentes solos. Este comportamento pode ser atribuído a maior interação com a fração sólida do solo do íon de potássio em relação ao nitrato, estando de acordo com os resultados encontrados por GONÇALVES et al. (2008). MIRANDA et al. (2005) verificaram que íons de potássio não acompanham a frente de molhamento do solo, sendo este fato atribuído à adsorção 
desses íons nos coloides do solo, enquanto GOMES et al. (2004) também observaram maior movimentação de íons de nitrato em solo arenoso em comparação com o solo argiloso.

\section{CONCLUSÕES}

O uso de extratores providos de cápsulas porosas para monitoramento da solução pode ser utilizado em solos de diferentes tipos de classes texturais, desde que sejam realizadas calibrações previamente. As análises nas soluções coletadas com extratores providos de cápsula porosa demonstraram haver superestimação para condutividade elétrica no solo arenoso, e para teor de nitrogênio nos dois tipos de solo estudados; e subestimação para os teores de potássio em ambos os tipos de solo, principalmente para o solo de textura argilosa.

\section{REFERÊNCIAS}

CASTELLANE, P.D.; ARAÚJO, J.A.C. Cultivo sem solo: hidroponia. Jaboticabal: FUNEP, 1994. $43 \mathrm{p}$.

COSTA, A.C.S.; SUZUKI, A.A.; LIBERDI, P.L.; PINTRO, J.C.; TORMENA, C.A.; SOUZA

JUNIOR, I.G.; SENGIK, E. Extração de $\mathrm{K}^{+}$e $\mathrm{Na}^{+}$por cápsulas de cerâmica porosa. Acta Scientiarum, Maringá, v.22, n.4, p.1.023-1.029, 2000.

DIAS, N.S.; DUARTE, S.N.; GHEYI, H.R.; MEDEIROS, J.F.; SOARES, T.M. Manejo da fertirrigação e controle da salinidade do solo sob ambiente protegido, utilizando-se de extratores de solução do solo. Revista Brasileira de Engenharia Agrícola e Ambiental, Campina Grande, v.9, n.4, p.496-504, 2005.

EMBRAPA. EMPRESA BRASILEIRA DE PESQUISA AGROPECUÁRIA. Sistema brasileiro de classificação de solos. Rio de Janeiro: CNPS, 1997. 212 p. (Documento, 1).

FERREIRA, P.A.; MARTINEZ, M.A. Movimento e modelagem de sais no solo. In: GHEYI, H.R.; QUEIROZ, J.E.; MEDEIROS, J.F. (Ed.). Manejo e controle da salinidade na agricultura irrigada. Campina Grande: UFPB/SBEA, 1997. cap.6, p.171-206.

GLOAGUEN, T.V.; PEREIRA, F.A.C.; GONÇALVES, R.A.B.; PAZ, V.S. Sistema de extração sequencial da solução na macro e microporosidade do solo. Revista Brasileira de Engenharia Agrícola e Ambiental, Campina Grande, v.13, n.5, p.544-550, 2009.

GOMES, E.R.S.; SAMPAIO, S.C.; CORRÊA, M.; VILAS BOAS, M.A.; ALVES, L.F.A.; SOBRINHO, T.A. Movimento de nitrato proveniente de água residuária em colunas de solos. Engenharia Agrícola, Jaboticabal, v.24, n.3, p.557-568, 2004.

GONÇALVES, A.D.M.A.; MIRANDA, J.H.; ROSSI, P.; SABADIN, J.F.G.; KAMOGAWA, M.Y. Temperature effect in potassium and nitrate ions in soil transport. Engenharia. Agrícola, Jaboticabal, v.28, n.3, p.438-447, 2008.

JIMÉNEZ, S.; ALÉS, J.I.; LAO, M.T.; PLAZA, B.; PÉREZ, M. Evaluation of nitrate quick tests to improve fertigation management. Communications in Soil Science and Plant Analysis, New York, v. 37, p. 2.461-2.469, 2006.

LAO, M.T.; JIMÉNEZ, S.; EYMAR, E.; FERNÁNDEZ, E.J. Nutrient levels of the solution obtained by means of suction cups in intensive tomato cultivation. Phyton, Buenos Aires, v.4, n.7, p. 29-37, 2004.

MARCUSSI, F.F.N.; GODOY, L.J.G.; VILLAS BÔAS, R.L. Fertirrigação nitrogenada e potássica na cultura do pimentão baseada no acúmulo de N e K pela planta. Irriga, Botucatu, v.9, n.1, p.41$51,2004$.

MEDEIROS, P.R.F.; DUARTE, S.N.; DIAS, C.T.S. Tolerância da cultura do pepino à salinidade em ambiente protegido. Revista Brasileira de Engenharia Agrícola e Ambiental, Campina Grande, v.13, n.4, p.406-410, 2009. 
MEURER, E.J.; ANGHINONI, I. Disponibilidade de potássio e sua relação com parâmetros de solo. Revista Brasileira de Ciência do Solo, Viçosa-MG, v.17, p.377-382, 1993.

MIRANDA, J.H.; DUARTE, S.N.; LIBARDI, P.L.; FOLEGATTI, M.V. Simulação do deslocamento de potássio em colunas verticais de solo não saturado. Engenharia Agrícola, Jaboticabal, v.25, n.3, p.677-685, 2005.

QUEIROZ, S.O.P.; TESTEZLAF, R.; MATSURA, E.F. Avaliação de equipamentos para determinação da condutividade elétrica do solo. Irriga, Botucatu, v.10, n.3, p.279-287, 2005.

QUEIROZ, S.O.P.; TESTEZLAF, R.; MATSURA, E. E. Metodologia para avaliação da salinidade do solo em ambiente protegido. Irriga, Botucatu, v.14, n.3, p.383-397, 2009.

RAIJ, B.van; ANDRADE, J.C.; CANTARELLA, H.; QUAGGIO, J.A. Análise química para avaliação da fertilidade de solos tropicais. Campinas, Instituto Agronômico de Campinas, 2001. $285 \mathrm{p}$.

ROSSI, P.; MIRANDA, J. H.; DUARTE, S.N. Curvas de distribuição de efluentes do íon nitrato em amostras de solo deformadas e indeformadas. Engenharia Agrícola, Jaboticabal, v.27, n.3, p.675$682,2007$.

RICHARDS, L. A. (Ed.) Diagnosis and improvement of saline and alkali soils. Washington: United States Salinity Laboratory, 1954. 160 p. (Agriculture Handbook, 60).

SILVA, E.F.F.; ANTI, G.R.; CARMELLO, Q.A.C.; DUARTE, S.N. Extratores de cápsulas porosas para o monitoramento da condutividade elétrica e do teor de potássio na solução de um solo. Scientia Agricola, Piracicaba v.57, n.4, p.785-789, 2000.

SOUZA, C.F.; FOLEGATTI, M.V.; MATSURA, E.E.; OR, D. Calibração da reflectometria no domínio do tempo (TDR) para a estimativa da concentração da solução no solo. Engenharia Agrícola, Jaboticabal, v.26, n.1, p.282-291, 2006.

SPOSITO, G. The chemistry of soils. New York: Oxford University Press, 1989. 277 p.

WERLE, R.; GARCIA, R.A.; ROSOLEM, A.C. Lixiviação de potássio em função da textura e da disponibilidade do nutriente no solo. Revista Brasileira de Ciência do Solo, Viçosa-MG, v.32, n.6, p. 2.297-2.305, 2008 . 